\title{
LA CIUDAD PUERTO DE SALINA CRUZ, MÉXICO: ESCENARIOS DE VULNERABILIDAD SOCIOAMBIENTAL
}

\section{THE PORT CITY OF SALINA CRUZ, MEXICO: SCENARIOS OF SOCIO-ENVIRONMENTAL VULNERABILITY}

\author{
Lilia Susana Padilla y Sotelo', Daniel Azevedo ${ }^{2}$ \\ 1 Universidad Nacional Autonoma de Mexico (UNAM), Cidade do Mexico, México \\ 2 Universidade Federal do Rio de Janeiro (UFRJ), Rio de Janeiro, RJ, Brasil
}

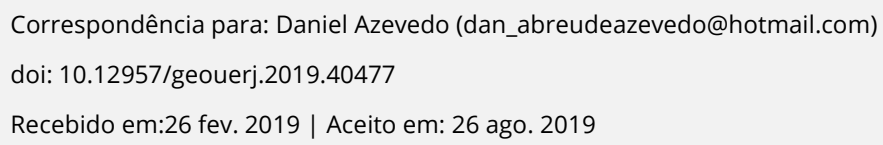

\section{RESUMEN}

Siguiendo la tendencia de la geografía contemporánea de reunir campos considerados dicotómicos, la geografía física y la geografía humana, este artículo tiene el objetivo de mostrar la relación entre ambos en un análisis de la vulnerabilidad socioambiental de la ciudad puerto de Salina Cruz a través de tres ejes. Un eje es el de las unidades geoecológicas obtenidas a partir del análisis de imágenes de satélite con una metodología de Aproximación Multiescalar, con la que se relacionan las características sociales del lugar. Otro eje es el de las Zonas Económicas Especiales que pretenden desarrollar puertos y la región aledaña ubicados en entidades federativas de rezago extremo como es Oaxaca en donde se localiza Salina Cruz. Un tercer eje que entrelaza a los otros es el de la Vulnerabilidad Socioambiental incapacidad de una comunidad para absorber los efectos de un cambio en su medio ambiente. A partir de ello se obtuvieron polígonos significativos de problemáticas socioambientales con una metodología del Índice de Aproximación, y se evidencia la severa situación de Salina Cruz ante eventos naturales a los que está sujeta y las características urbanas deficientes para enfrentar este tipo de fenómenos.

Palabras-clave: Vulnerabilidad socioambiental. Zoneamiento geoambiental. Polígonos de vulnerabilidad. Salina Cruz. Mexico.

\begin{abstract}
Following the contemporary geography to gather fields considered dichotomous, physical geography and human geography, this article aims to show the relationship between those two in an analysis of the socio-environmental vulnerability of the port city of Salina Cruz through three axises. One axis is that of the geoecological units obtained from the analysis of satellite images with a Multiscale Approach methodology, with which the social characteristics of the place are related. Another axis is that of the Special Economic Zones that seek to develop ports and the surrounding region located in states of extreme backwardness such as Oaxaca, where Salina Cruz is located. A third axis that interweaves the others is that of the Socio-environmental Vulnerability inability of a community to absorb the effects of a change in its environment. After that, polygons of socio-environmental problems were obtained with an Approximation Index methodology, and the severe situation of Salina Cruz is evidenced by natural events to which it is subjected and the urban characteristics that are deficient to face this type of phenomenon.
\end{abstract}

Keywords: Socioenvironmental vulnerability. Geoambiental zoning. Vulnerability polygons. Salina Cruz. Mexico.

\section{INTRODUCCIÓN}

La relación entre elementos de la naturaleza y factores antropogénicos (en toda su extensión sea social, cultural, política, ambiental etc.) resulta de gran complejidad y la geografía en las últimas décadas estuvo muchas veces alejada del análisis que uniera a ambos aspectos como resultado de la dicotomía entre 
geografía física y geografía humana. Nuestro artículo sigue la tendencia de trabajos contemporáneos que buscan construir nuevos puentes entre esos dos campos de conocimiento de la ciencia geográfica, mostrando que la cuestión de la vulnerabilidad socioambiental es un tema de interfaz entre geografía física y geografía humana.

En este caso se encuentra la ciudad puerto Salina Cruz (México) que registra severos problemas socioambientales que derivan en una situación que dificulta el desarrollo de la población y la localidad, al presentar un escenario de alta vulnerabilidad socioambiental. No obstante, la ciudad está considerada en el contexto del proyecto de las Zonas Económicas Especiales que supuestamente desarrollarán puertos en busca de cerrar brechas de desigualdad entre el norte y sur del país. Con base a este contexto es que el artículo está estructurado.

El objetivo del estudio es revelar la vulnerabilidad socioambiental de la ciudad puerto de Salina Cruz ubicada en el estado de Oaxaca (México), tomando en consideración diversos factores que la han propiciado, como la creación de la refinaría de Petróleos Mexicanos (PEMEX) en 1979. Para ello, se crean polígonos significativos de vulnerabilidad socioambiental derivados de su irregular expansión urbana costera, de su localización en una zona de alto riesgo sísmico y ser una de las tres entidades con mayores rezagos sociales y económicos del país ${ }^{1}$, aspectos que necesitan ser tomados en consideración para el desarrollo del proyecto de las Zonas Económicas Especiales creado en 2017 que supuestamente beneficiaria social y económicamente a la localidad portuaria.

A partir de lo antes expuesto, el trabajo se compone de tres partes, además de la parte introductoria y las conclusiones: la primera se orienta el objeto de estudio y la metodología. La ciudad de Salina Cruz y sus características geográficas también son consideradas porque nos ayudarán a revelar y entender causas de su vulnerabilidad socioambiental. El trabajo se desarrolla con una ruta metodológica de tipo cualitativo-cuantitativo y carácter interdisciplinar, ya que combina técnicas de investigación de varias

\footnotetext{
${ }^{1}$ Además del estado de Oaxaca, en donde se ubica la ciudad de Salina Cruz, los estados colindantes de Chiapas y Guerrero son considerados los que registran mayores rezagos sociales y económicos del país.
} 
disciplinas sociales, incluso con la interpretación de imágenes producidas por Sistemas de Información Geográfica (SIG). Entretanto, el artículo explica con la metodología aplicada que el análisis de nuevas tecnologías no excluye el uso de algunas tradicionales dentro de la ciencia geográfica, como es el trabajo de campo, ya que el reconocimiento en terreno permitió corroborar las problemáticas observadas, no solo en los polígonos significativos seleccionados, también en el resto de la localidad.

En un segundo momento, otra parte es la perspectiva de análisis de zoneamiento geoambiental que es usada a modo de construcción que entrelaza como una especie de puente los conocimientos de la geografía física y la geografía humana, a partir de conceptos como riesgo, amenaza y desastre que están incluso dentro del concepto de vulnerabilidad socioambiental. La tercera y última parte es medular para la investigación, ya que se presentan los resultados obtenidos a través de las metodologías aplicadas y el análisis de los polígonos implementados. Así buscamos contribuir a revelar dinámicas complejas socioespaciales de Salina Cruz y ayudar a crear nuevos puentes entre los conocimientos producidos por la geografía física y la geografía humana.

\section{CASO DE ESTUDIO Y METODOLOGÍA}

Caso de estudio: la ciudad puerto de Salina Cruz (Oaxaca - México)

La ciudad de Salina Cruz se localiza en el estado de Oaxaca (Figura. 1) al sureste de México en el municipio del mismo nombre, hacia la Bahía de Salina Cruz, al norte del Golfo de Tehuantepec del Pacífico Mexicano, al sur del Istmo de Tehuantepec y al sureste de México. 

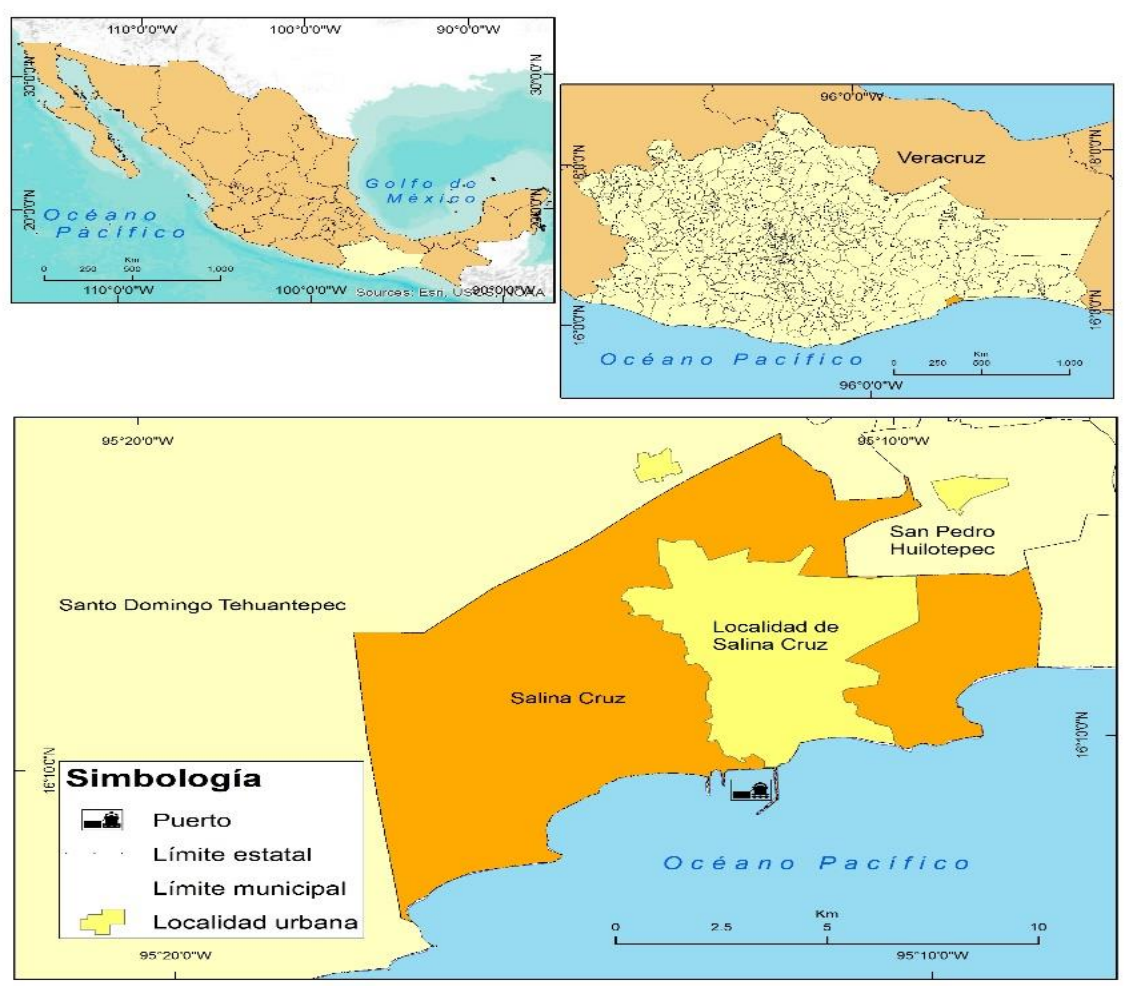

Figura 1. Localización de la ciudad y puerto de Salina Cruz en los contextos nacional, estatal y municipal. Fuente: Elaboración propia con datos de INEGI, SINCE 2010

El municipio de Salina Cruz colinda al este con el municipio de San Pedro Huilotepec, al este con el de Santo Domingo Tehuantepec y al sur con el Océano Pacifico, exactamente con el Golfo de Tehuantepec, por lo que cuenta con potencial pesquero. Debido a que en su territorio se encuentra una cadena de cerros, su altitud promedio es de aproximadamente 40 metros sobre el nivel del mar, por lo que en general carece de grandes elevaciones, aunque la existencia de cerros en la periferia de la localidad de Salina Cruz es considerable.

La situación geológica de Salina Cruz es fundamental para comprender su vulnerabilidad socioambiental, ya que "geológicamente pertenece a una costa de choque o colisión entre la Placa Oceánica de Cocos y la Placa Americana de naturaleza continental, lo que origina frecuentes y fuertes sismos y exhibe una fisonomía de barreras arenosas que da lugar al establecimiento de lagunas costeras extensas". Además, “masas de aire frío de invierno conocidas como nortes, entre los meses de octubre y abril afectan al municipio y localidad” (Toledo-Campo, 1994 apud ORTÍZ y DE LA LANZA, 2006, p.25). Estas masas de aire pasan a través del istmo y se conocen como "Tehuanos" o "Tehuantepecanos", por lo que en la 
zona se produce una surgencia de agua fría y rica en nutrientes, que es un fenómeno oceanográfico (op cit, p. 27).

Tormentas tropicales también son comunes en Salina Cruz, ya que se encuentra junto con Guerrero y Chiapas en una zona de huracanes, según la Comisión Nacional del Agua (CONAGUA) es en el Golfo de Tehuantepec, perteneciente a Oaxaca, donde se forman más de la mitad de eventos de este tipo en la temporada en el Pacífico Mexicano, debido a la temperatura del agua y las corrientes de aire cálido que circulan en la zona, principalmente durante los meses de septiembre y octubre (RAMIREZ, 1998; CERDA, 2001), sin embargo la temporada empieza hacia mayo, como fue el caso de la tormenta Calvin en 14 de junio de 2017 que afectó severamente a Salina Cruz.

El análisis de la vulnerabilidad socioambiental de la ciudad de Salina Cruz toma en consideración que su desarrollo está involucrado con su característica de ciudad puerto. Salina Cruz es considerada como un puerto regional, pero por el alcance del abasto de combustibles que realiza, puede calificarse también como puerto de importancia nacional. Participa con el 5\% de la carga transportada por vía marítima en el país, ya que traslada productos petroleros principalmente a los puertos del Pacífico Mexicano de Lázaro Cárdenas y Manzanillo para ser distribuidos en regiones aledañas (SCT, API SALINA CRUZ, 2019) como más adelante se detalla.

El puerto de Salina Cruz es artificial multipropósito, considerado como uno de los 16 principales puertos de México $^{2}$. En el mismo el acceso al antepuerto es a través de dos rompeolas que delimitan el canal de acceso, constantemente dragado para evitar que se azolve. A pesar de tener más de 100 años no es un puerto que destaque en el contexto portuario nacional mexicano; no obstante que está catalogado como puerto de altura y cabotaje, petrolero y comercial, centro logístico nacional y regional, con potencial para ser eslabón de un corredor productivo comercial y logístico de la zona que constituye el Corredor

\footnotetext{
${ }^{2}$ El sistema portuario mexicano se compone de 98 puertos y 16 terminales habilitadas, 56 en el litoral Pacífico y 58 en el litoral del Golfo de México y Caribe; del total de puertos, 66 realizan tráfico de altura y cabotaje y 48 sólo cabotaje (SCT, API Salina Cruz, 2019).
} 
Industrial Interoceánico que une al propio puerto de Salina Cruz con el de Coatzacoalcos del vecino estado de Veracruz, situado hacia el Golfo de México.

Maneja tráfico de carga de la región sur y sureste de la República Mexicana, comprende el estado de Oaxaca y los de Chiapas, Veracruz, Campeche, Tabasco, Quintana Roo y Yucatán entre otros. Su zona de influencia se superpone con la de otros puertos comerciales como Acapulco, Lázaro Cárdenas y Puerto Chiapas. La mayor actividad del puerto es petrolera, el 90\% de su manejo comercial es el petróleo y sus derivados. Es clave para exportar combustible a otros puertos como Manzanillo y Lázaro Cárdenas, pues en la ciudad de Salina Cruz está la refinería más grande del país llamada “Antonio Dovalí Jaime” de Petróleos Mexicanos (PEMEX) (SEMAR DIGAHOM s/f).

En ese contexto, ductos y tanques de almacenamiento de PEMEX son elementos del paisaje de Salina Cruz y tienen un papel fundamental en el análisis de la vulnerabilidad socioambiental, pues se mezclan en espacios en donde se ubica población con distintas condiciones sociales que se refleja tanto en las viviendas como en las precarias condiciones de algunos de los espacios públicos. A ello hay que agregar el riesgo sísmico y el deslave que puede ocurrir en la temporada de tormentas tropicales en los cerros existentes en esta localidad.

\section{METODOLOGÍA}

Para la obtención de unidades de paisaje se desarrolla una metodología multicriterio (visual - espacial) y multiescalar (local - regional), en el nivel local se concretiza en función de la homogeneidad relativa de su comportamiento (PRIEGO et al, 2008) y en el nivel regional los paisajes de - nivel local - son componentes de unidades mayores - nivel regional - que se repiten y difunden en las unidades superiores de manera típica y regular (BOLLO y HERNÁNDEZ, 2008). Se analizan imágenes Landsat 8 de octubre del 2015, con combinación de color natural o real y composición del color de acuerdo a la información relativa a las intensidades de luz de los tres colores básicos. 
El trabajo se lleva a cabo con una ruta metodológica de tipo cualitativo-cuantitativo y carácter interdisciplinar, ya que combina técnicas de investigación de varias disciplinas sociales. Se utilizaron técnicas cuantitativas y cualitativas para el manejo de experiencias y observaciones de algunos habitantes del lugar por medio de conversaciones in situ. Se le da especial realce al trabajo de campo, para no solo conocer la conformación de la vulnerabilidad socioambiental, también corroborar los espacios en conflicto, que son los polígonos analizados en donde se detectaron problemáticas severas derivadas de situaciones sociales y ambientales.

El trabajo de campo se efectuó en el año de 2017 en el mes de agosto, poco antes del fuerte terremoto que afectó a la región el 7 de septiembre de ese año, los participantes eran investigadores y becarios de posgrado del proyecto del que forma parte este trabajo. Cabe destacar que también era temporada de campaña electoral para cambio de Gobernador del Estado, lo cual mantenía un ambiente de gran movimiento y hasta festivo en la localidad.

Se realizaron entrevistas a autoridades de dependencias del gobierno local, así como a habitantes de la ciudad, se aplicó la técnica de entrevistas ya estructuradas para conocer la opinión y conocimiento acerca de los riesgos a los que se encuentra expuesta la localidad y su población. Las autoridades fueron cautelosas en la respuesta, y consideraron que el gobierno estaba realizando constantes trabajo para hacer conciencia en la gente de las acciones que debían tomar en cuenta para enfrentar posibles catástrofes, tanto por las afectaciones de las instalaciones, ductos y tanques de almacenamiento de PEMEX, ya fuera en una conflagración como un incendio, en sismo o una tormenta tropical. En contraste los habitantes se mostraron molestos con el gobierno ya que no hace campañas constantes para saber qué hacer en los casos como los citados; incluso manifestaron que PEMEX debería de llevar a cabo campañas para explicar las acciones que deberían considerar ante estos eventos y en donde resaltaron el gran riesgo que se observa en las porciones de los polígonos seleccionados, como más adelante se menciona.

El recorrido por la localidad permitió corroborar los resultados de gabinete en la obtención de los polígonos, ya que se observó la realidad que vive la población de cualquier nivel socioeconómico, aunado 
a la problemática derivada de aspectos físicos del lugar (sismos y tormentas tropicales) y enfatizar el peligro que representa la refinería de PEMEX que abarca hasta el puerto hacía donde se dirigen directamente ductos que trasladan combustible y que constituyen un riesgo en el momento de cargar los buque tanques.

Las tecnologías de la Información Geográfica desarrollan diferentes campos de investigación y su relevancia la representa la obtención de unidades definidas por la homogeneidad como en unidades que cuentan a su interior con características homogéneas entre ellas, y lo suficientemente heterogéneas para ser diferenciadas al exterior, lo que facilita el análisis, evaluación y planificación-gestión de los impactos producto de procesos antropogénicos (MARTÍNEZ y BOLLO, 2017). En Salina Cruz las unidades geoecológicas registran principalmente clases de cobertura terrestre y uso del suelo: habitacional, infraestructura y en menor escala área verde, área cultivada y suelo degradado que serán explicadas en los resultados, que muestran un espacio multifuncional con interacción y vinculación resultado de constante cambio.

Las unidades del paisaje, aparte del nivel jerárquico al que responden, están constituidas por una síntesis de componentes (PRIEGO et al, 2008). Para la obtención de esas unidades del paisaje se utilizó el mapa de paisajes físico-geográficos y una tipología que integra cobertura terrestre y uso del suelo, que representa la estructura antropogénica del paisaje del territorio. Tipología que, al superponerse a los paisajes físico-geográficos, permite identificar a la vez unidades geoecológicas (BOLLO et al, 2013).

La metodología aplicada enfatiza la aproximación multiescalar: en un primer paso se analizan las unidades físico-geográficas (paisajes naturales) a escala 1:100.000, en el segundo paso se analizan a escala 1:50.000, cobertura terrestre y uso del suelo representativo del espacio geográfico-relacional en el contexto social-económico; el último paso es la definición de las unidades geoecológicas con una evaluación de la calidad geoecológica del paisaje, mediante la caracterización y el análisis del comportamiento espacial de las unidades en el contexto local, que fueron catalogadas de acuerdo a la morfología de la cubierta urbana, tomando en cuenta lo interpretado por observación en las imágenes del área de estudio. 
Para realizar una evaluación geoecológica se utilizó para ese artículo el Sistema de Información Geográfica, teniendo como base un modelo digital del relieve en el que sobrepone uso del suelo y vegetación. Con la aplicación de esta metodología se tiene ya una primera aproximación en la que se detecta una combinación de cobertura terrestre y uso del suelo que se presenta en los resultados en la tabla 1.

Para los polígonos, usamos la metodología desarrollada por Molina (2016) quien la realizó para mostrar la segregación residencial en la ciudad puerto de Salina Cruz $^{3}$ en espacios específicos, que resultan idóneos para mostrar la vulnerabilidad socioambiental a la que está sujeta la ciudad puerto. Para la obtención de los polígonos aplicó un Índice de Proximidad en una matriz de correlación que expresan una agrupación residencial por clase social, cuya proximidad revela una característica de vecindad relacionada de cruzar dos variables, asoció grado de escolaridad y ocupantes por vivienda, y grado de escolaridad y servicios que presentaron correlación positiva y permitieron la delimitación de polígonos.

\section{PERSPECTIVA DE ANÁLISIS}

Como afirma Mateo (2004) hay numerosos estudios sobre lo urbano, lo ambiental y sus interrelaciones. No obstante, quedan temas por debatir, y surgen nuevas aristas que permiten el desarrollo de aproximaciones conceptuales y metodológicas ante el amplio y abarcador tema de la interrelación ambiente y urbanización. Es cada vez más común en la literatura geográfica la búsqueda para borrar la dicotomía histórica entre naturaleza y sociedad dentro de los estudios de esa ciencia (DREW, 1994; ROSS y SANCHEZ, 2009; COSTA, 2011). Es en ese sentido que nuestro artículo se orienta.

La década de 1960 trajo un bagaje crítico importante dentro de la geografía, pero al mismo tiempo significó la gota de agua final para el alejamiento general entre lo que se denomina "geografía humana" y "geografía física" (CASTREE et al, 2009), pues, "lo que antes fuera el núcleo de la identidad geográfica ya no parecía más ser en las décadas de 1980” (SOUZA, 2018, p. 290). En los últimos años,

\footnotetext{
${ }^{3}$ Cuyos resultados se presentaron en una conferencia en el XXII Congreso Nacional de Geografía San Luis Potosí 2016.
} 
sin embargo, es dentro de la denominada "Geografía Ambiental" o "geoambiental" que se aprecia la discusión para ese diálogo de saberes, entre las miradas sociogeográfica y ecogeográfica (SCHIRNER y ROBAINA, 2018, SOUZA, 2018).

Uno de los interesantes modos que esas conexiones están siendo construidas se refiere a la práctica de la Zoneamiento Geoambiental, producto final de nuestro artículo a partir de los polígonos de vulnerabilidad socioambiental de Salina Cruz. El Zoneamiento Geoambiental revela las complejas dinámicas entre elementos de la naturaleza y sociales, y junto al concepto de vulnerabilidad nos ayuda a identificar áreas de riesgo y a producir políticas públicas de calidad. Según Schirner y Robaina:

\footnotetext{
La Zonificación proporciona la organización del área en sistemas y unidades con características ambientales similares en cuanto a las potencialidades y restricciones de uso y ocupación debido a las condiciones actuales del área, referentes a las características físicas y acción antrópica que construir su dinámica actual. De esta forma, puede ser visto como un instrumento de ordenamiento territorial que busca identificar las restricciones y las aptitudes ambientales naturales en cuanto al uso y la ocupación humana. (SCHIRNER y ROBAINA, 2018, p.205).
}

Barrientos (2017) sistematiza una visión consecuente con la construcción social del riesgo, en el contexto de la relación sociedad-naturaleza para establecer la vulnerabilidad socioambiental a partir de la siguiente secuencia. Considera que se parte de la amenaza (peligro de la manifestación en espacio y tiempo de un fenómeno de origen natural, socio-natural o antropogénico, que puede producir efectos adversos en las personas, la producción, la infraestructura, los bienes y servicios y el ambiente); el desastre (situación o proceso social que se desencadena como resultado de la manifestación de un fenómeno de origen natural, tecnológico o provocado por el hombre que, al encontrar condiciones propicias de vulnerabilidad en una población, causa alteraciones intensas, graves y extendidas en las condiciones normales de funcionamiento de la comunidad) y son representadas de forma diversa y diferenciada. Pueden citarse la pérdida de vida y salud de la población, la destrucción, pérdida o inutilización total o parcial de bienes en la localidad y los individuos, así como daños severos en el ambiente.

Este mismo autor también enuncia que la vulnerabilidad es la condicionante del desencadenamiento de las condiciones que cualifican al "desastre", de su magnitud, consecuencias y diferenciación espacio- 
temporal y social. Es factor de riesgo interno de un elemento o grupo de elementos expuestos a una amenaza, correspondiente a su predisposición intrínseca a ser afectado, de ser susceptible a sufrir un daño, y de encontrar dificultades en recuperarse posteriormente. Corresponde a la predisposición o susceptibilidad física, económica, política o social que tiene una comunidad de ser afectada o de sufrir efectos adversos en caso de que un fenómeno peligroso de origen natural o causado por el hombre se manifieste.

Finalmente, Barrientos (2017) expresa que las diferencias de vulnerabilidad del contexto social y material expuesto ante un fenómeno peligroso determinan el carácter selectivo de la severidad de sus efectos. Lo anterior conduce al riesgo, es decir, a la probabilidad que se presente un nivel de consecuencias económicas, sociales o ambientales en un sitio particular y durante un período de tiempo definido.

En el mismo orden de ideas Cardoso manifiesta que:

\footnotetext{
los grupos humanos se sitúan en diferentes posiciones frente a las amenazas latentes, propias del momento histórico y del lugar en que viven. La vulnerabilidad, como uno de los componentes del riesgo, es la incapacidad o inflexibilidad de una comunidad para absorber los efectos de un cambio en su medio ambiente (crisis económicas, desastres de diversas causas). Dicha incapacidad está conformada por características, tanto individuales como sociales y del entorno que habitan. Es posible distinguir niveles de vulnerabilidad socioambiental, su distribución en el territorio es un reflejo de los modos de desarrollo fragmentado, destacándose el papel de los servicios públicos básicos en la satisfacción de las necessidades (CARDOSO, 2017, p.156).
}

Los análisis de los autores anteriores son importantes porque revelan que la idea de "factor antrópico" debe de ser tomada con atención. La complejidad social incluye cuestiones sociales, culturales, políticas que no se puede resumir con la idea sencilla de "factor antrópico" (AZEVEDO, 2017). Hay especificidades en los contextos espaciales que son importantes para un análisis geográfico, como es el caso de Salina Cruz por ser una ciudad portuaria.

Las ciudades puerto poseen sus especificidades en la relación sociedad-naturaleza (MATEO, 2004), como es nuestro caso de estudio. Fedele y Domínguez (2015), consideran que la infraestructura portuaria gradualmente se ha ido descubriendo como un proyecto de diseño urbano. Ciudad y puerto 
componen un binomio indivisible, cuyo denominador común es el hombre que trabaja y habita en el sitio. En las ciudades puerto la relación entre la infraestructura portuaria y la ciudad ha sido fructífera, pero también ha sido problemática y forman una relación en incesante transformación con cambios sobre los puertos que afectaron el entorno natural en las últimas décadas del siglo XX, que han inducido a la redefinición del rol del puerto y su lugar en la planificación urbana. Así, los recintos portuarios se convirtieron en parte del diseño urbano, problema común a las ciudades portuarias.

De manera que se genera un espacio multifuncional y polivalente en las zonas de interacción entre un puerto y la ciudad en que se ubica, dando lugar a una dinámica de vinculación en constante cambio (SÁNCHEZ, 2003). A lo que se puede agregar que en estos procesos en ocasiones las instalaciones portuarias van quedando obsoletas, por la continua necesidad de más espacio para sus expansivas actividades globales de tráfico comercial (FEDELE y DOMINGUEZ, 2015). De manera que la ciudad en su crecimiento renueva sus funciones y requiere de espacios para sus constantemente modificados modelos de uso y valoración urbana.

En ese contexto los paisajes litorales entre los que se encuentran los portuarios (MARTÍNEZ y BOLLO, 2017) se ven afectados por una urbanización que coloniza los lugares más privilegiados y por los múltiples impactos generados por la diversidad de actividades relacionadas con el puerto como son carreteras, ferrocarril, edificaciones, industria entre otros, lo que provoca degradación del espacio geográfico como resultado del desarrollo urbano e industrial primordialmente.

Así, además de los retos socioambientales que una ciudad ya tiene, al caso de Salina Cruz se agrega las dificultades de ser una zona portuaria. Como la Figura 2 nos muestra hay dos conjuntos de cuestiones socioambientales a las que una ciudad puerto necesita poner atención 


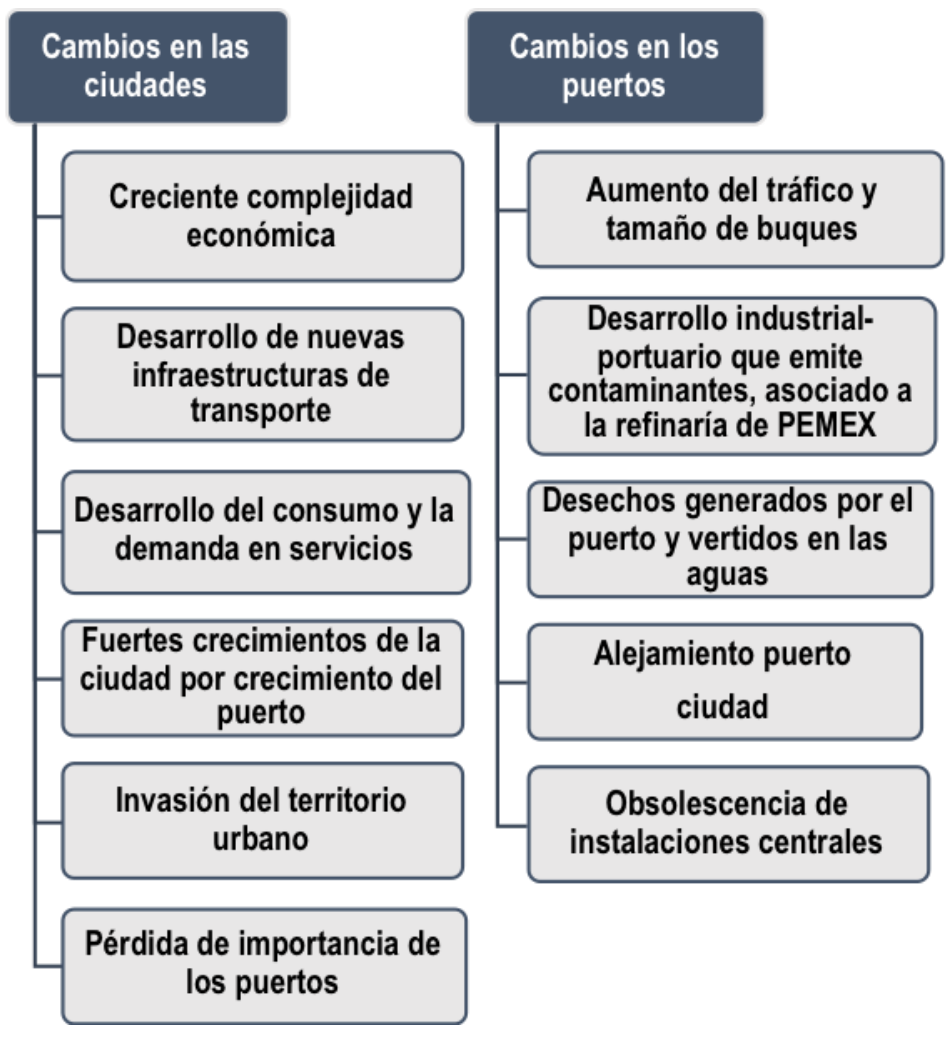

Figura 2. Conflictos en el binomio ciudad puerto de Salina Cruz - Vulnerabilidad socioambientalFuente: elaboración propia de los autores en base a datos de Sepúlveda, 2011

Cabe enfatizar que el puerto en cuestión desempeñaba un papel de importancia a mediados del siglo pasado, no obstante, actualmente en sus particularidades locacionales, es considerado como un puerto “perdedor" (OJEDA, 2011) ya que no presenta condiciones adecuadas para su desarrollo económico a pesar de encontrarse hacía la Cuenca del Pacífico (la zona comercial más importante a escala mundial).

En ese contexto en función de que el "crecimiento" de un puerto es medido por el incremento en la carga (principalmente, la contenerizada) por ingresos, y como unidad económica asentada en una región de influencia y ligada al ciclo económico o nivel de actividad que viene desarrollando México, en su relación comercial, de acuerdo a Boisier (1998) algunos puertos han quedado en "exclusión económica y social" situación que incorpora el com $\neg$ ponente geográfico, entendiendo la exclusión asociada a regiones y territorios olvidados, y por supuesto, a las personas y actores sociales excluidos como puede considerarse en cierta medida a Salina Cruz - reflejo de regiones conectadas y desconectadas del mundo global. 
En 2015 se promulgó la ley para la creación de cuatro Zonas Económicas Especiales, a partir de lo cual se ha implementado al puerto de Salina Cruz, sin embargo, la vulnerabilidad socioambiental puede agravarse si ese proyecto no toma en cuenta los factores localizacionales de la ciudad. El proyecto de las Zonas Económicas Especiales en México busca disminuir el rezago que tienen los estados del sur respecto a los del norte y la región de El Bajío, ya que hoy coexisten dos "Méxicos": por un lado, uno moderno, con altas tasas de crecimiento, integrado a la economía global y muy competitivo, y, por otro, uno con menor nivel de desarrollo, altos niveles de marginación y pobreza, y donde predominan actividades de baja productividad (ZAMORA, 2018), ello ha creado brechas económicas con contrastes sociales en el país. El proyecto se inició con las ZEE ubicadas a partir de los puertos de Lázaro Cárdenas (Michoacán), Salina Cruz (Oaxaca) y Puerto Chiapas (Chiapas) en el Pacífico Mexicano y Coatzacoalcos (Veracruz) en el Golfo de México, a las que posteriormente se les han adicionado otras.

La literatura sobre ZEE la pone como política de Estado para crear nuevas localizaciones industriales, como un nuevo tipo de extraterritorialidad. Sobre la base justificativa de atraer inversiones externas, garantizar el acceso a las tecnologías modernas y desarrollar las regiones, el Estado delimita un territorio para capitales en busca de valoración, donde existe disponibilidad de energía, infraestrutura y mano de obra (BRAGA y PELIN, 1989; EGLER, 1989). A pesar de no ser el objetivo de nuestro estudio, cabe mencionar que hay fuertes críticas a los modelos de ZEE como proyectos de desarrollo territorial, como se ve en Ávila y Romero (2017) sobre la población indígena en México.

Se tiene que en el Diario Oficial de la Federación se ha asignado un polígono localizado en el municipio de Salina Cruz con uya superficie de 4,598-97 hectáreas para la creación de la ZEE de Salina Cruz. Decreto que entró en vigor a partir del 20 de diciembre de 2017 (PASANTES, 2017). Así Salina Cruz es una de estas ZEE, a la vez es uno de los polos del - extremo sur - del Corredor Industrial Interoceánico del Istmo de Tehuantepec (que podría ser una ruta alternativa al Canal de Panamá), considerado a través de la historia como punto estratégico para el comercio internacional, al registrar la distancia más corta en el país entre el Golfo de México y el Oceánico Pacífico (304km por ferrocarril y $314 \mathrm{~km}$ por carretera) (Figura 3). Junto con el Puerto de Coatzacoalcos - extremo norte de dicho corredor - se busca consolidar en el largo plazo no sólo un corredor logístico sino industrial en la región. 
En ese sentido, tanto para el Programa de Desarrollo de la ZEE de Salina Cruz como de Coatzacoalcos, deberá contemplarse un análisis sobre las oportunidades que existen en el corredor como una franja sobre la cual se dará valor agregado a bienes y servicios en tránsito a lo largo del mismo, con objeto de incorporar en dichos programas acciones específicas para detonar este potencial (SHCP Y ZEE, S/f).

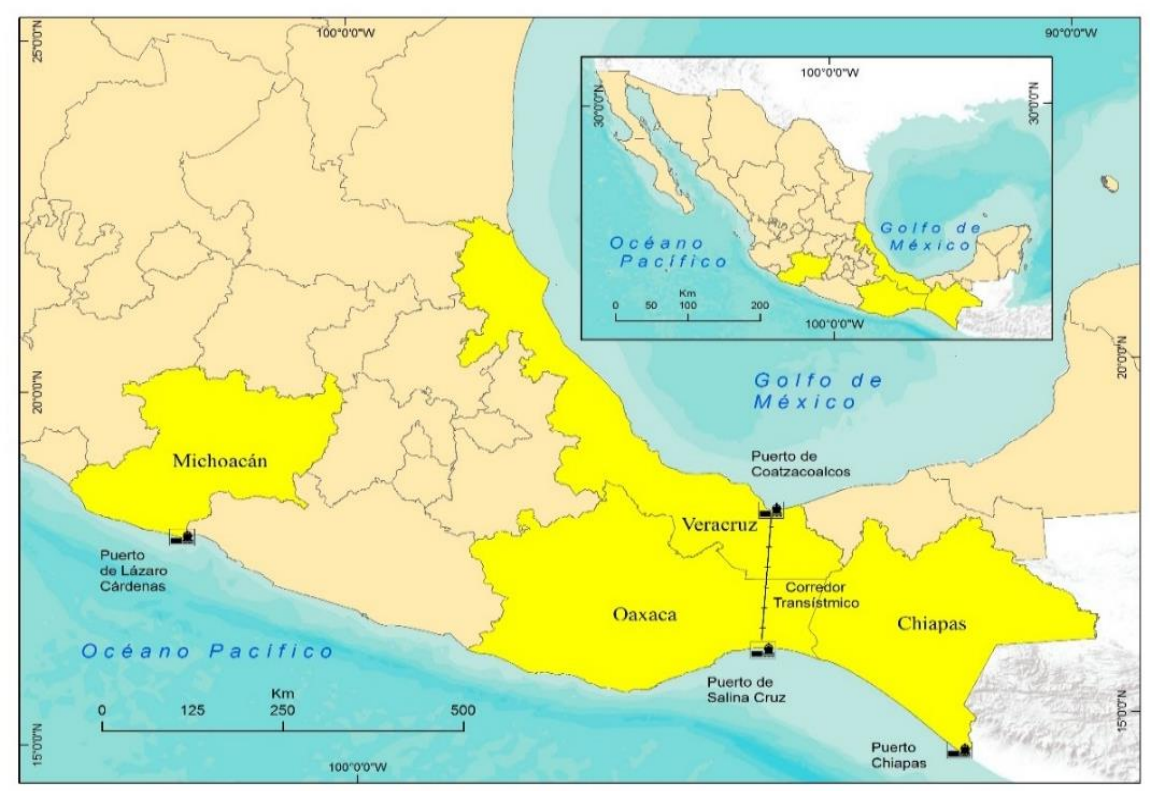

Figura 3. Localización de las Zonas Económicas Especiales y el Corredor Interoceánico del Istmo de Tehuantepec Fuente: elaboración propia, con datos de AFDZEE, 2017

Se advierte que las citadas actividades afectan recursos como el agua, los humedales y la cobertura vegetal, debido a que Salina Cruz está situada en uno de los paisajes naturales más frágiles, el costero (GRUBER et al, 2003). Así, creamos un zoneamiento geoambiental de vulnerabilidad a partir de la metodología seleccionada con tres polígonos significativos de problemáticas generadas por las actividades económicas de las áreas, como las relacionadas con PEMEX.

De igual modo, se agregó el riesgo que representa el ubicarse en una zona de alta sismicidad, como ya se señaló, y que se evidenció en los daños derivados de los fuertes sismos del 7 de septiembre de 2017 que tuvo afectaciones severas en viviendas, vías de acceso y vialidades por citar algunas. Así como registrar escenarios adversos, ya que la localidad está rodeada de cerros en los que hay viviendas en riesgo por las tormentas tropicales y por los sismos, pero que no cuentan con vialidades y que en emergencias afectan el acceso. 
Como corolario puede decirse que en Salina Cruz se ha registrado expansión urbana irregular derivada de la inmigración que ha recibido de diferentes estados del país, atraída por las fuentes de trabajo que supuestamente ofrecen Petróleos Mexicanos y la Administración Portuaria Integral, que han generado presión sobre los recursos naturales (agua y suelo principalmente) y si bien han proporcionado fuentes de trabajo, estas han originado severos problemas convirtiendo a Salina Cruz en una localidad de gran vulnerabilidad socioambiental

\section{RESULTADOS}

Una vez considerada la ruta metodológica, en primera instancia se tienen las unidades geoecológicas con las clases de cobertura terrestre y uso del suelo, las primeras pueden soportar varios de los segundos. Las que se obtuvieron para la ciudad puerto de Salina Cruz con la metodología aplicada se presentan en la Tabla 1. En donde se enfatizan aquellas en las se ubican los polígonos de vulnerabilidad socioambiental desarrollados más adelante.

\section{CLASES DE \\ COBERTURA \\ TERRESTRE}

Habitacional

Infraestructura

Área Verde

Vegetación

Área Cultivada

\section{CARACTERISTICAS DEL USO DEL SUELO}

$\{$ infr Hace referencia al uso habitacional compacto continuo y denso, asociado a infraestructura vial y servicios. Que es característico de una ciudad, aunque en Salina Cruz a muchos contrastes.

Son instalaciones diversas: centros comerciales (la más importante es la plaza Pabellón Salina Cruz), restaurantes, centros de servicio, templos (como la Parroquia de la Sagrada Familia, las Capillas de Juriquilla, San Felipe de Jesús la de la Divina Providencia etc) centros recreativos-deportivos, bancos (de todas las instituciones bancarias), institutos( Instituto Tecnológico de Salina Cruz), universidades (Universidad del Istmo, Universidad del Pacífico), escuelas, hospitales, oficinas, clubes sociales, etc. La refinería de PEMEX, tanto edificaciones o instalaciones, como redes o trazados para transporte, energético (ductos de PEMEX) y sanitario, pozos de almacenamiento o plantas de tratamiento, industrias e instalaciones que afectan de manera similar al uso industrial como grandes depósitos, talleres, subestaciones eléctricas o bodegas industriales.

$\int$ Es el conjunto de especies vegetales que habitan una región, de acuerdo al Sistema de Clasificación de la Vegetación del INEGI (Instituto Nacional de Estadística y Geografía). Existe pocas áreas verdes originales matorrales, pastizales y arbustos $\left\{\begin{array}{l}\text { Comprende zona agrícola, cubierta de vegetación modificada por el hombre con } \\ \text { cultivos permanentes, transitorios y misceláneos o especializados que en la ciudad } \\ \text { de Salina cruz no se presentan }\end{array}\right.$ 
Suelo Degradado $\quad\left\{\begin{array}{l}\text { Suelos que han experimentado procesos de degradación y/o deterioro, bien sea de } \\ \text { origen natural (deslaves) o antrópico (con fines de extracción o recuperación) se } \\ \text { pueden citar las zonas de líneas de ductos, los cerros en donde se encuentras los } \\ \text { tanques de almacenamiento de combustible de PEMEX) }\end{array}\right.$

Tabla1. Unidades geoecológicas: cobertura terrestre y uso del suelo en la ciudad puerto de Salina Cruz Tehuantepec Fuente: elaboración propia a partir de la metodología aplicada

Nota: en las clases sombreada de amarillo se encuentran las zonas en donde se ubican los polígonos de vulnerabilidad socioambiental considerados en ese artículo

Queda claro a partir de lo anteriormente expuesto que la mayor actividad del puerto es la relacionada con la cuestión petrolera, ya que el $90 \%$ de su manejo comercial es el petróleo y sus derivados. Es clave para exportar combustible a otros puertos como Manzanillo y Lázaro Cárdenas, pues en la ciudad de Salina Cruz está una de las refinerías más grandes del país llamada “Antonio Dovalí Jaime” de Petróleos Mexicanos (PEMEX), sin embargo, actividades relacionadas con esta y con el puerto, como son los ductos que atraviesan la ciudad para ser reunidos en tanques o bien conducidos a los barcos petroleros son aspectos que afectan la localidad y en consecuencia a los polígonos seleccionados.

Algunas personas entrevistadas en trabajo de campo se quejan de la contaminación por gases emitidos por la refinería que afectan a la ciudad, o bien algunos incidentes registrados dentro de la refinería, como una sobrepresión que se registró en la misma el 16 de enero de 2018 y que fue corroborado con información de un periódico local en línea, en un editorial de Matías (2018). Y en ocasiones en derramas en las maniobras de descarga de los ductos en los barcos que afectan a la fauna marina, situaciones que se observaron directamente en el trabajo de campo y entrevistas a personas locales.

En otro orden de ideas además de las técnicas de SIG e interpretación de imágenes, se corroboro directamente en terreno la sobreposición de infraestructura urbana de tipo habitacional fragmentada y mezclada con equipamiento de servicios e industrias (ductos de traslado de hidrocarburos, tanques de almacenamiento de combustóleo con alto riesgo para la población y afectaciones al medio ambiente) Se observó bajas condiciones socioeconómicas por calidad de viviendas en gran parte de la ciudad, así como la carencia de infraestructura de servicios en varias zonas, la reducida pavimentación en las calles de la localidad, e incluso la carencia de vialidades en las porciones habitadas en los cerros (Figura 4). Solo el 
$40 \%$ de la extensión urbana cuenta con pavimento en las calles, el resto es empedrado o adoquinado o simplemente no cuenta con recubrimiento (INEGI, 2015).

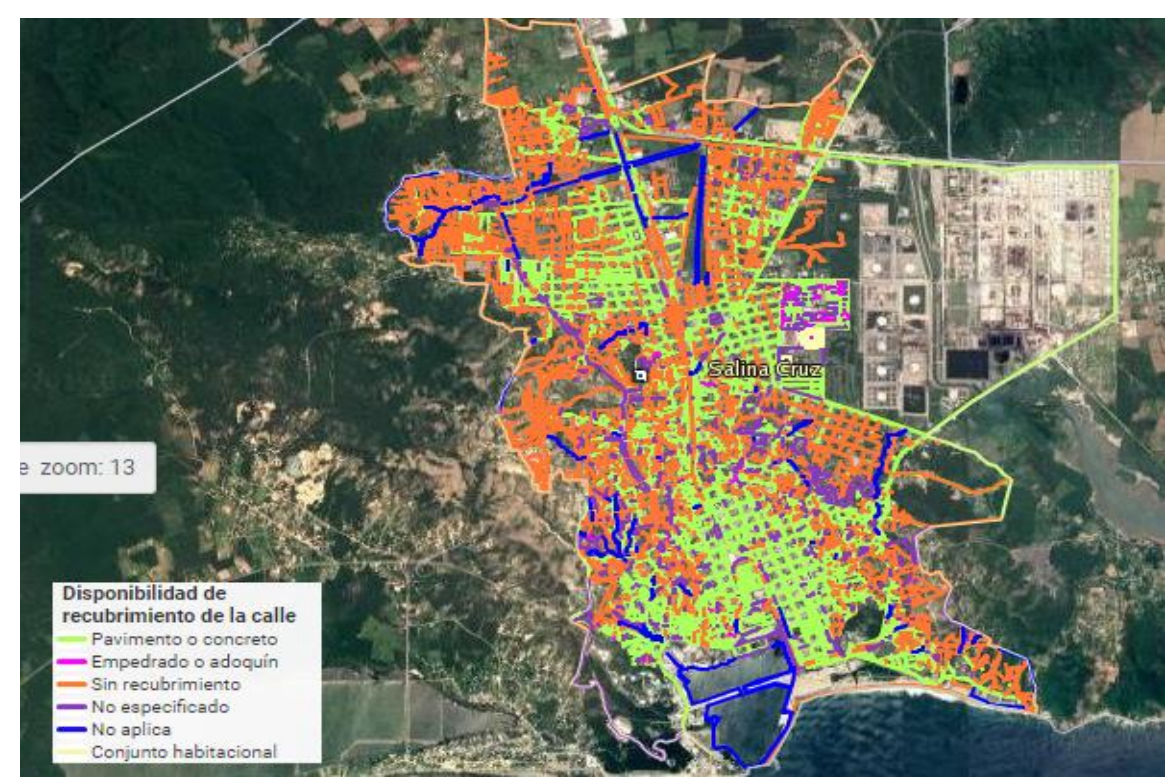

Figura 4. Disponibilidad de recubrimiento en las calles de la ciudad de Salina Cruz Fuente: Inventario Nacional de Vivienda, INEGI

Para explicarse las causas de las deficiencias que se observan en la localidad de Salina Cruz, hay que tomar en cuenta lo que ocurre en el estado de Oaxaca, que registro más de 3,8 millones de habitantes para el censo de 2010, distribuidos en 570 municipios, de los 2457 con que cuenta el país, muestra una gran fragmentación que redunda en dificultad para su gobierno y estudio. Solo 11 municipios clasifican con grado "muy bajo" de marginación, que equivalen únicamente el $12 \%$ de su población, entre los que se encuentra Salina Cruz. Se concluye un comportamiento con predominio "alto-muy alto" de grado de marginación, característico de altas carencias materiales para el conjunto de la población, esto es reflejo de dismetrías sociales muy marcadas y se significación de condiciones adversas para su desarrollo social y económico en el contexto estatal.

Es "apreciable el contraste de "muy bajo" grado de marginación con respecto al de toda la entidad federativa, en el municipio de donde está enclavado el puerto de Salina Cruz y la refinería de PEMEX, lo que al parecer es directamente proporcional (o que coincide), con el mayor influjo económico condicionado por estas actividades portuaria y petrolera, en detrimento del resto de las unidades 
municipales de dicho estado que en general se encuentran bastante rezagadas" (SHCP Y ZEE s/f., p. $9)$.

En ese contexto las cifras pueden ser engañosas, ya que en el ámbito estatal la gran mayoría de municipios de Oaxaca registran "alto y muy alto" grado de marginación como se expresó anteriormente. Y no obstante que el municipio de Salina Cruz ocupa el lugar 563 en el estado considerando como "muy bajo" grado de marginación (que son las mejores condiciones) y el lugar que ocupa a escala nacional es el 2256 (también con mejores condiciones); así como presentar un grado de rezago "muy bajo”. Si bien puede aseverarse que el contexto no es negativo localmente, pero si en los contextos regional y estatal se encuentra en una zona de grandes carencias (SEDESOL, 2019). Aun cuando el municipio de Salina Cruz registra un grado de marginación "muy bajo", sus condiciones no se pueden comparar con algunos otros municipios que registran este mismo valor, pero de regiones del norte del país.

En la Figura 5 se muestra el grado de marginación del estado de Oaxaca en achurado, además se asocia con las viviendas dañadas por los sismos del 7 de septiembre de 2017 que oscilaron entre 501 y 1120 . El municipio de Salina Cruz se delimito con color azul.

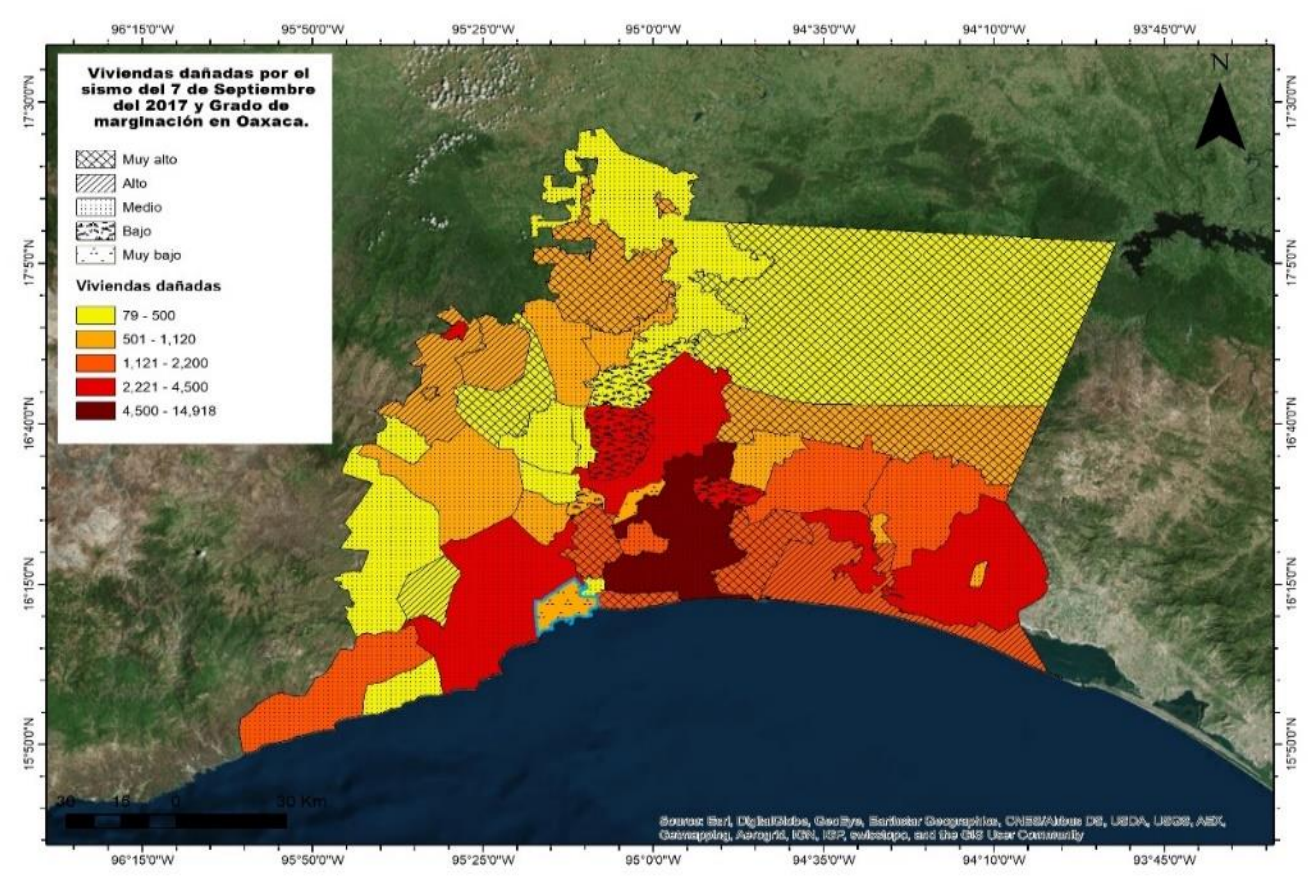

Figura 5. Grado de Marginación y Viviendas dañadas por los sismos de 2017 en el estado de Oaxaca Fuente: CONAPO, $2015 \mathrm{y}$ 
Lo anterior da muestra del interés de incorporar a Salina Cruz en el proyecto de las Zonas Económicas Especiales, ello se observa en lo que se expresa en un dictamen emitido para la ZEE de Salina Cruz (SHCP y ZEE, S/f.: 9) "uno de los requisitos para el establecimiento de una ZEE que se obtiene teniendo como requisito ubicarse en las entidades federativas que, a la fecha de la emisión del Dictamen, se encuentren entre las diez entidades federativas con mayor incidencia de pobreza extrema" de acuerdo con la información oficial del Consejo Nacional de Evaluación de la Política de Desarrollo Social (CONEVAL).

Además, en estas zonas supuestamente se podrán desarrollar procesos que impactaran en las dinámicas socioespaciales al proponer transformaciones que establecen cambios en sistemas de vida y de producción del espacio y que están, en el caso de Salina Cruz, en las industrias como la del vestido, la de maquinaria y equipo y la relacionada con energías renovables en otras, y evidentemente por la presencia del puerto y la refinería.

Con base a lo anterior, hay que enfatizar que Salina Cruz, aun cuando forma parte de esa entidad con graves deficiencias, tiene algunos elementos que pueden incidir en su desarrollo, entre los que se incluyen: contar con un puerto estratégico para las economías del litoral del Pacífico Mexicano, ya que a través de él PEMEX abastece de combustibles a los estados de dicho litoral. Asimismo, es de relevancia su ubicación en el Istmo de Tehuantepec que se encuentra en el contexto de los ejes y corredores multimodales de la globalización, con un enfoque conceptual estructural-sistémico con potencial que ubica a la unidad de análisis en un sistema-mundo cada vez más articulado, a través de un espacio de redes y flujos (PADILLA Y DE SICILIA, 2017).

Por el puerto de Salina Cruz empresas y consumidores de la región istmeña efectúan exportaciones e importaciones comerciales, con los estados del litoral del Pacífico, así como, en menor escala, con Estados Unidos, Europa, Japón y China, entre otros países, se comercian productos en contenedores, carga general, granel agrícola y mineral. En términos de acceso a mercados internacionales por el Pacífico, el puerto representa el nodo intermodal más económico para la región Sur - Sureste del país, pero no ha 
logrado posicionarse a la altura de Manzanillo, Lázaro Cárdenas y Acapulco, situados en el mismo litoral (SCT, API SALINA CRUZ, 2017).

Las anteriores diferencias regionales se reflejan en los puertos de México, por lo que con las ZEE se pretende desarrollar puertos y regiones que supuestamente se vislumbran con potencial. "Sin embargo el desarrollo de la ZEE de Salina Cruz resulta sumamente incierto y en realidad se ha quedado en cuestiones mediáticas y no se advierten trabajos directos en el territorio y con la población, los cuales propicien beneficios para la ciudad puerto, tal como lo manifiesta la propia población en entrevistas y se advierte en recorridos por la localidad" (PADILLA Y DE SICILIA 2017, s/p)

A partir de sus características localizacionales, fue posible construir un mapa con tres polígonos de alta vulnerabilidad socioambiental. Eso no significa que no hay peligro en otras áreas de la ciudad, sin embargo, esos tres polígonos fueron considerados de alto riesgo en la medida de que en la relación de factores naturales (como potencial de riesgo asociado a presencia de cerros), factores sociales (como débil infraestructura, condiciones de las viviendas, y características de la población) y económicos (presencia de equipos relacionados el manejo de hidrocarburos, como tanques y ductos) registraban mayor vulnerabilidad que el resto de la localidad.

\section{Polígonos de vulnerabilidad socioambiental}

Es de significancia para la vulnerabilidad socioambiental asociar la localidad con problemas naturales como los sismológicos, a los que se agregan situaciones específicas relacionadas con la Refinería de PEMEX, por ejemplo, se tiene que el 13 de junio de 2017, PEMEX emite un comunicado que al calce dice:

\footnotetext{
"derivado de las fuertes lluvias provocadas por la tormenta tropical Calvin, diversas áreas de la refinería en Salina Cruz resultaron inundadas. Se procedió a un paro de operaciones. Las inundaciones tuvieron como consecuencia el desbordamiento de residuos y el derramamiento de aceite. Este producto alcanzó un punto de ignición resultado de las afectaciones por la inundación, desatando un incendio, el cual se sofocó el día 16 de junio. El 22 de junio después de una evaluación se puso en marcha un programa con acciones en tres líneas: reanudación de operaciones; limpieza y rehabilitación del sitio afectado y mantenimiento general, aprovechando
} 
el paro obligado. Se estima reiniciar las operaciones el 30 de julio" (Pemex, 2017, apud PADILLA Y DE SICILIA, 2017, s/p.).

La situación en la ciudad de Salina Cruz se intensificó negativamente con el sismo de 8,2 grados acontecido el 7 de septiembre de 2017, registrándose severas afectaciones, ya que el epicentro de este sismo se localiza cerca de Salina Cruz en el Golfo de Tehuantepec, el cual sacudió el sureste y el sur del país de acuerdo con el Servicio Sismológico Nacional (SSN). Además de ese temblor, se registraron otros cinco sismos de entre 4 y 5.1 grados de magnitud en la región, se afectaron porciones del Istmo de Tehuantepec en su porción oaxaqueña, en donde se localiza Salina Cruz (PADILLA Y DE SICILIA, 2017).

La refinería de Salina Cruz suspendió sus operaciones la noche del terremoto del 7 de septiembre 2017, cuando apenas llevaba 16 días de operación, tras sufrir afectaciones por inundaciones y una explosión.

\footnotetext{
Había estado parada 70 días, reinició sus operaciones el 22 de agosto y 16 días después volvió a suspenderlas tras el citado sismo, que, aunque no causó daños estructurales, afectó el funcionamiento de sus turbogeneradores que alimentan la electricidad. En su momento la empresa reconoció que los fenómenos hidrometeorológicos de agosto y los sismos de septiembre disminuyeron sustancialmente la capacidad de refinación, por debajo de lo programado; las contingencias por estos eventos originaron el paro de la producción (PADILLA Y DE SICILIA, $2017, \mathrm{~s} / \mathrm{p})$
}

En el caso que aquí atañe, la vulnerabilidad socioambiental resulta de asociar estos resultados con las instalaciones de PEMEX a partir del Índice de Proximidad, como fue explicado en la metodología. sean la propia refinería, los ductos o los tanques de almacenamiento de esta institución e incluso la zona del puerto en donde llegan los ductos para abastecer a los barcos de productos provenientes de PEMEX. Cabe señalar que en Salina Cruz cualquier tipo de edificación, vivienda, comercio, industria etc. se encuentra expuesta a la cercanía de instalaciones relacionadas con PEMEX. A lo anterior se puede añadir nuevamente la zona de alta sismicidad en que se ubica Salina Cruz.

En la Figura 6 se presentan en un mapa central a escala Áreas Geoestadísticas Básicas (AGEBs) ${ }^{4}$ los polígonos considerados para enfatizar la zona de alto riesgo sísmico y las porciones de mayores

\footnotetext{
${ }^{4}$ Área geográfica conformada por un conjunto de manzanas, delimitada por calles, andadores, el uso de suelo es principalmente habitacional, industrial, etc
} 
afectaciones por el sismo del 2017 a nivel regional que causó gran devastación. En la parte superior derecha se muestra con gradientes el nivel de intensidad del sismo, se aprecia que la ciudad puerto de Salina Cruz se ubica en el área en rojo de más daño. El mapa donde aparecen los polígonos se ubica en un recuadro rojo para resaltar su ubicación en la zona más cercana al epicentro del sismo citado.

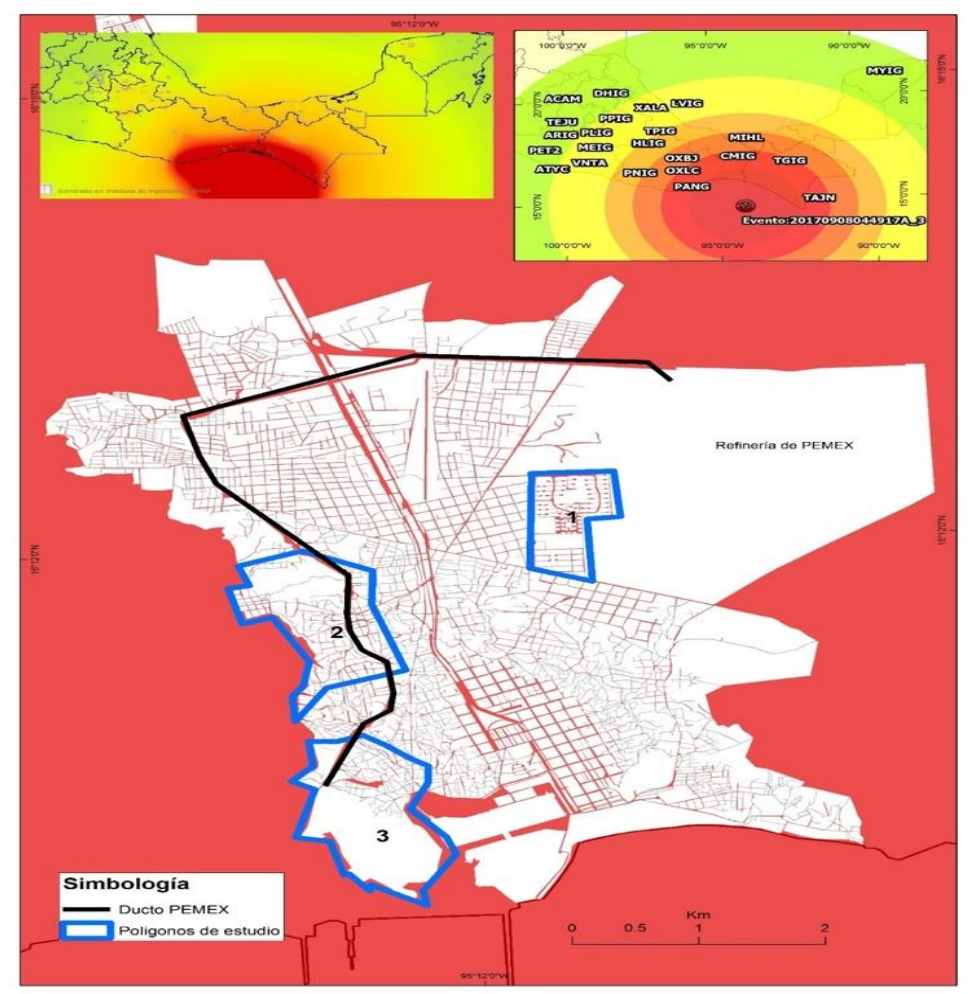

Figura 6: Polígonos Extremos de vulnerabilidad socioambiental Fuente: elaboración propia con datos de Servicio Sismológico Nacional, 2017, Áreas Geoestadísticas Básicas (s/f) y Molina, 2016)

Polígono 1. Es el que presenta mejores condiciones, referente a educación su población cuenta con alto grado de escolaridad, de 13.2 años de acuerdo al promedio del municipio que es de 9.0 y en el estado de Oaxaca es de 7.5. En cuanto a ocupantes por vivienda registra solo 3.1 (INEGI, 2010). Un 50\% de las viviendas se ubican en un fraccionamiento de acceso controlado que cuenta con mayor seguridad, y que corresponde a la Colonia Petrolera, que además tiene protección militar; de tal manera que son viviendas con estructuras arquitectónicas adecuadas y seguras. Asimismo, se localiza en una porción plana de la localidade 
En trabajo de campo se apreció que es una zona en donde se encuentran las mejores viviendas de la localidad, para empleados de PEMEX, todas las calles están pavimentadas, sin embargo, su proximidad a la refinería hace a este polígono altamente vulnerable por su cercanía, precisamente, a la refinería y por ubicarse en zona de alta sismicidad (Figura 7).

En junio de 2017 la tormenta Calvin generó una inundación y explosión en la refinería de PEMEX, hubo derramamiento de aceite y el producto alcanzó viviendas. El polígono 1 tuvo que ser desalojada, pues el humo negro indicaba que miles de litros de combustibles y derivados podrían afectar las viviendas y salud de los ciudadanos.
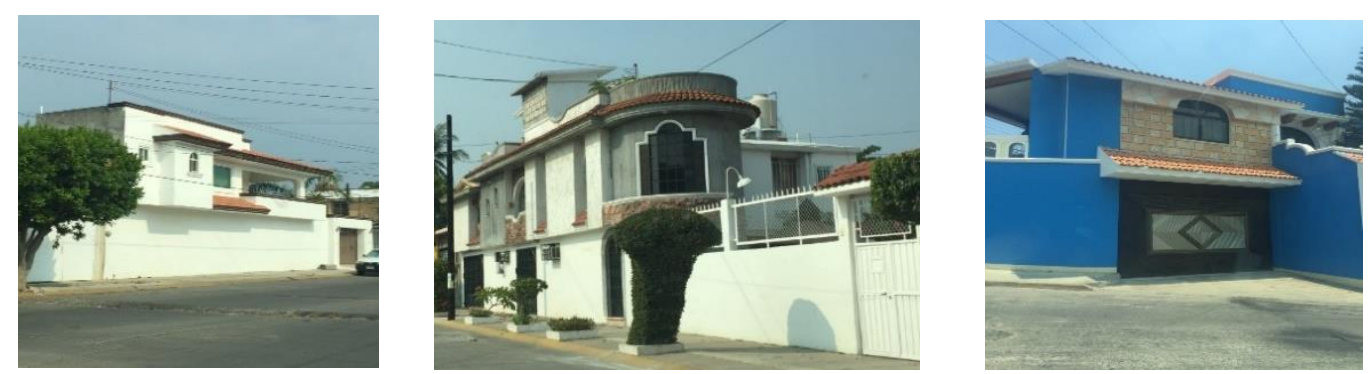

Figura 7: Viviendas en el Polígono 1 Fuente: Fotografías tomadas en trabajo de campo agosto de 2017.

Polígono 2. Es el que registra las peores condiciones, su población muestra un grado de escolaridad de solo 6 años, muy por debajo de los niveles estatal y municipal. Presenta una irregularidad estructural marcada en las viviendas, ya que muchas de ellas son de cartón y materiales totalmente inseguros (SEDATU, 2017). Numerosas viviendas se encuentran en cerros en donde no se cuenta con suficientes vías de acceso, y en muchos casos hay que subir escaleras en inclinación de hasta 60 grados. Se agrega que sólo $10 \%$ de las pocas calles existentes están pavimentadas. Presenta comercios que además están enrejados por la inseguridad que se registra, situación que también se aprecia en las viviendas, muchas de las cuales son irregulares en tenencia y construcción y registran hacinamiento de sus ocupantes de bajos recursos.

En trabajo de campo se corroboró las numerosas deficiencias en este polígono al cual atraviesa uno de los diez ductos que cruzan a la localidad que trasladan productos desde la refinería a tanques de 
almacenamiento ubicados en el polígono 3 o bien se direccionan a los barcos que los trasladarán a otras entidades del Pacífico Mexicano (Figura 8). Por tanto, también es de alta vulnerabilidad socioambiental.
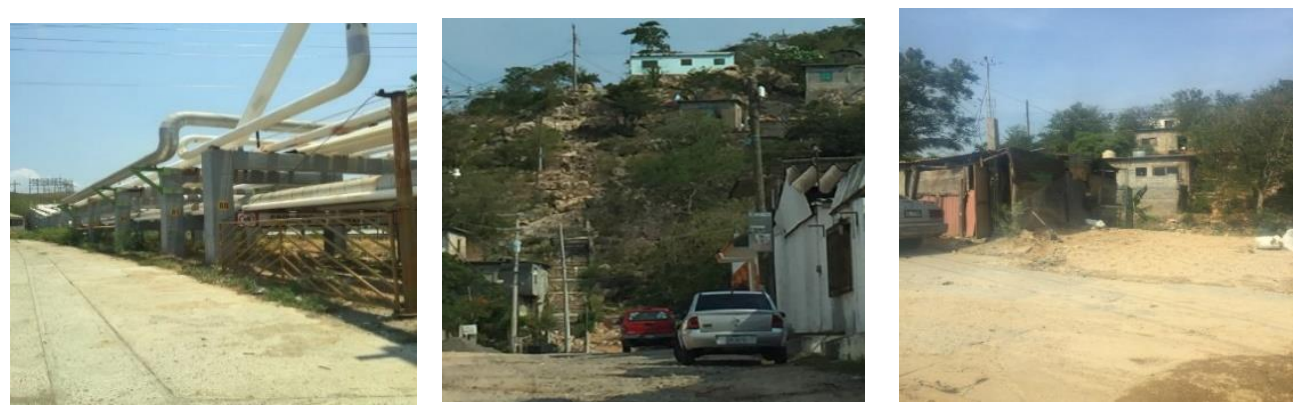

Figura 8 Viviendas y Ductos que atraviesan el Polígono 2Fuente: Fotografías tomadas en trabajo de campo agosto de 2017

Polígono 3. Presenta condiciones intermedias, grado promedio de escolaridad de su población que es de 9.1. Aproximadamente solo la mitad del polígono tiene pavimento, las viviendas registran condiciones de intermedia a baja. Cuenta con cerros en donde se localizan los tanques de almacenamiento de combustóleo de PEMEX, además una porción muestra que también lo atraviesa el ducto que conduce desde la refinería a hasta los tanques diversos productos, que después se direccionan a los barcos.

Resultado de réplicas del terremoto del 7 de septiembre de 2017 de 8.2 grados en la escala Richter se suscitó una pequeña fuga en la línea que suministra de crudo a la Boya 3 en la zona de carda de la Terminal Marítima de Pemex (PEMEX, 2017). PEMEX señaló que las altas vibraciones provocaron que un espárrago que embrida la línea se degollara, lo que generó un pequeño goteo de crudo, y personal especializado se encuentra realizando trabajos de contención para reparar dicha fuga, pero la línea se encuentra fuera de operación (JAB, 2017)

En trabajo de campo se observó que los tanques de almacenamiento se encuentran en los cerros con peligro de deslave, pues es una zona que las masas de aire producen fuertes tormentas. La población estuvo en peligro en la tormenta Calvin en 2017, pues hubo derramamiento de aceite y muchos tuvieran que salir de sus casas. Incluso su cercanía al puerto en la porción rentada a PEMEX, le hace igualmente de alta vulnerabilidad socioambiental (Figura 9). 


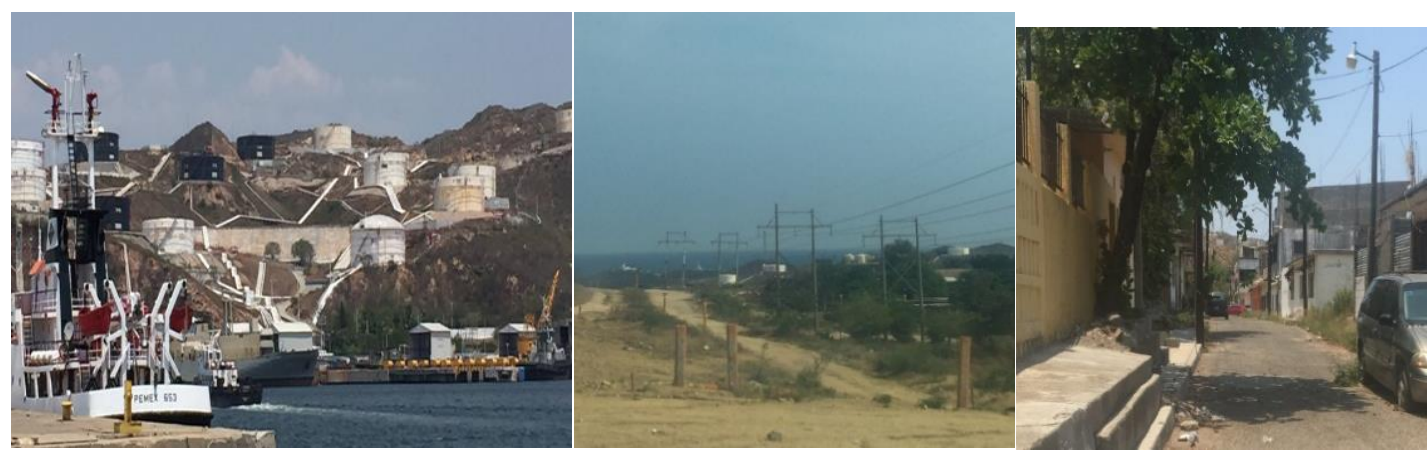

Figura 9 Tanques de almacenamiento de combustóleo y área portuaria de suministro de ductos a barcos, viviendas y calles.

Nesta conjuntura, tornam-se necessário apresentar as práticas sociais dos camponeses e suas estratégias para que possamos compreender como eles se comportam no lugar.

\section{CONCLUSIONES}

Las ciudades portuarias son lugares con sociedades que ponen a la vista características sistémicas, que se alejan de los contextos de equilibrio que muestran un comportamiento complejo y no lineal.

La aplicación de la metodología para la obtención del zoneamiento geoambiental resulta de utilidad, ya que permite valorar el aspecto físico-geográfico de los paisajes en los que se asienta la población de la ciudad-puerto de Salina Cruz como resultado de la interacción naturaleza-ocupación de la actividad humana.

Estas unidades resultan importantes en los análisis de cuestiones sociales, económicas y ambientales, es decir de la interacción entre la naturaleza y la sociedad, de la apropiación de la segunda de la primera y sus consecuencias. La metodología con que se obtienen muestra que sus resultados son útiles para la planificación de un territorio.

La ciudad de tipo pequeña de Salina Cruz tiene una función industrial a nivel nacional y poco aporta al desarrollo local debido a que más del 80\% de los derivados industriales proceden de PEMEX y salen de la ciudad vía marítima por el puerto ubicado en la localidad, que tiene concesionada a PEMEX una parte de sus instalaciones.

Las grandes diferencias regionales en México se reflejan en sus puertos, por lo que con las Zonas Económicas Especiales se pretende desarrollar puertos y regiones que supuestamente se vislumbran con 
potencial. Sin embargo, el desarrollo de la ZEE de Salina cruz resulta sumamente incierto y en realidad se ha quedado en cuestiones mediáticas y no se advierten trabajos directos en el territorio y con la población que propicien beneficios para la ciudad puerto, tal como lo manifiesta la propia población en entrevistas y se advierte en recorridos por la localidade.

Se proponen las ZEE como una alternativa para disminuir desigualdades regionales en México, creando nuevos polos de desarrollo a partir de espacios que cuentan con elementos para su logro, no obstante, las críticas existentes. La ZEE del puerto de Salina Cruz fue seleccionada debido a su ubicación estratégica en el Istmo de Tehuantepec, en donde se pretende desarrollar el Corredor Industrial Interoceánico cuyos parámetros extremos son los puertos de Salina Cruz y Coatzacoalcos, con la finalidad de unir el Pacifico Mexicano y el Golfo de México.

Se pretende corregir con la implementación de la ZEE en función del potencial que registra, el retraso de la ciudad puerto de Salina Cruz que registra severos problemas de infraestructura, carece de aeropuerto, el puerto no permite el acceso de barcos de gran calado, por lo que este binomio ha quedado excluido del modelo global, no obstante, su localización estratégica.

Finalmente, nuestro estudio mostró una metodología que coadyuva a eliminar la dicotomía histórica entre los conocimientos de la geografía física y la geografía humana, a partir de una perspectiva que no pretende decir que uno es mejor que el otro, sino que busca mostrar la forma e importancia de utilizar y relacionar ambos, tal como se aprecia en este caso, ya que se aprecia que los dos son igualmente importantes, ya que con su interrelación se logró mostrar la alta vulnerabilidad socioambiental de la ciudad puerto de Salina Cruz

\section{BIBLIOGRAFÍA}

AUTORIDAD FEDERAL PARA EL DESARROLLO DE LAS ZONAS ECONÓMICAS ESPECIALES, (AFDZEE) 2017. Las Zonas Económicas Especiales, 2017. Disponible en: https://www.gob.mx/se/articulos/las-zonas-economicas-especialesde-mexico (Acceso el 25 de agosto 2017).

AVILA, A.; ROMERO, L. E. A. Las nuevas Zonas Económicas Especiales en México: despojo agrario y resistencia campesina. Revista Nera, $N^{\circ} 40$ Vol 20, p.60-73, 2017.

AZEVEDO, D. A. O papel da geografia no debate sobre o meio ambiente: superando dicotomias. Revista Geouerj, Rio de Janeiro, n. 31, p. 456-473, 2017. 
BARRIENTOS, P. Un factor de Riesgo para la salud de la población del estado de Veracruz: presencia de aflatoxinas en ganado bovino y su ingesta a través de la leche. Tesis (Doctorado en Geografía), Universidad Nacional Autónoma de México, 2017.

BOISIER, S. El desafió territorial de la globalización. Reflexiones acerca del Sistema Regional chileno en Economía, Sociedad y Territorio. El Colegio Mexiquense, A.C Vol. I, Núm. 4, p. 755-777, 1998.

BOLLO, M.; HERNÁNDEZ, J. R. Paisajes físico-geográficos del noroeste del estado de Chiapas, México. Revista Investigaciones Geográficas. v.12, n.7, p.7-24, 2008.

BOLLO, M., HERNÁNDEZ, J. Y MÉNDEZ, A. Áreas de atención prioritaria en México: una óptica medio ambientale. Journal of Latin American Geography, v. 12, No. 2, p. 63-84, 2013).

BRAGA, C.; PELIN, E. Zonas de Processamento de Exportaç̃os: A Experiência Internacional. In: PELIN, E.R., SILBER, S.D. e ANGELO, I.P., Zonas de Processamento de Exportacẽos. Q Debate. IPE/USP, São Paulo, 1989, p. 11-44.

CARDOSO, M. Estudio de la vulnerabilidad socio-ambiental a través de un índice sintético. Caso de distritos bajo riesgo de inundación: Santa Fe, Recreo y Monte Vera, Provincia de Santa Fe, Argentina. Caderno de Geografia, vol. 27, núm. 48, enero-marzo, 2017, pp. 156-183, 2017.

CASTREE, N. DEMERITT, D.; LIVERMAN, D.; RHOADS, B. (Orgs.). A Companion to Environmental Geography. Malden, MA: Wiley-Blackwell, 2009.

CERDA, M. E. H. Los ciclones tropicales de Mexico. Ciudad de Mexico: UNAM, 2001.

CONSEJO NACIONAL DE POBLACIÓN. Índice de Marginación Urbana, Salina Cruz Estado de Oaxaca Región Istmo (2010). Disponible en:

http://www.conapo.gob.mx/es/CONAPO/Datos_Abiertos_del_Indice_de_Marginacion. Acceso 23 de enero de 2019.

DREW, D. Processos interativos homem-meio ambiente. Rio de Janeiro: Bertrand Brasil, 1994.

EGLER, C. As Zonas de Processamento de Exportaç̃es e a Gestão do Território. Reflexões Preliminares. In: CARLEIAL, L. e NABUCO, M.R. (org.). Transformações na Divisão Inter-regional do Trabalho no Brasil. ANPEC/CEDEPLAR, São Paulo/Belo Horizonte, 1989, p.75-89.

FEDELE, J. Y DOMINGUEZ, R. Puerto y ciudad. Revista Transporte y Territorio n. 12, Universidad Nacional del Litoral, Argentina, p.13-29, 2015.

GRUBER, N. L. S.; BARBOZA, E. G.; NICOLODI, J. J. Geografia dos sistemas costeiros e oceanográficos: subsídios para gestão integrada da zona costeira. Revista Gravel, n. 1, p.81-89, jan. 2003.

INSTITUTO NACIONAL DE GEOGRAFÍA Y ESTADÍSTICA (INEGI) Áreas Geoestadísticas Básicas Marco Geoestadístico General (s/f). Disponible en: https://www.inegi.org.mx/temas/mapas/mg/. Acceso 20 de enero de 2019.

INSTITUTO NACIONAL DE GEOGRAFÍA Y ESTADÍSTICA (INEGI) Censo General de Población y Vivienda. (2010), Disponible en:http://www.inegi.org.mx/est/contenidos/proyectos/ccpv/cpv2010/Default.aspx. Acceso 2 de octubre 2017.

INSTITUTO NACIONAL DE GEOGRAFÍA Y ESTADÍSTICA (INEGI) (SINCE Sistema para la Consulta de Información Censal (SINCE) (2010). Disponible en

https://www.google.com/search?q= since+inegi\&oq=since+inegi\&aqs=chrome.69i57j012.6983j0j8\&sourceid=chrome\&i $\mathrm{e}=$ UTF-8. Acceso 19 de febrero de 2018.

INSTITUTO NACIONAL DE GEOGRAFÍA Y ESTADÍSTICA (INEGI) Inventario Nacional De Vivienda (INV) (2015)

Disponible en:http://www.beta.inegi.org.mx/app/mapa/inv/.Acceso 11 de febrero de 2019. 
JAB, R. Temblor ocasionó fuga de Pemex y deja tres playas de Salina Cruz contaminadas. Disponible en:https://regeneracion.mx/temblor-ocasiono-fuga-de-pemex-y-deja-tres-playas-de-salina-cruz-contaminadas/.Acceso el 2 de octubre 2017.

MATEO, J. El medio ambiente y la sostenibilidad urbana desde una perspectiva espacial. El Cable Revista de Arquitectura. Universidad Nacional de Colombia, Sede Manizales, Numero 3, p. 57-70, 2004.

MARTINEZ. A., Y BOLLO, M. Aplicación del enfoque geoecológico para la interpretación espacial de los niveles de urbanización. Economía, Sociedad y Territorio, Vol. XII No. 53, p. 115-144, 2017.

MATÍAS P. Pemex confirma “incidente" en refinería de Salina Cruz por "sobrepresión"; no hay lesionados ni afectaciones. Disponible en:https://pagina3.mx/2019/01/pemex-confirma-incidente-en-refineria-de-salina-cruz-porsobrepresion-no-hay-lesionados-ni-afectaciones/.Acceso 23 deoctubre de 2018.

MOLINA, I. Segregación residencial en los límites de las instalaciones petroleras en Salina Cruz, Oaxaca. XXII Congreso Nacional de Geografía, San Luis Potosi, del 5 al 7 de julio de 2016. México, 2016.

OJEDA, N. Los puertos mexicanos en el siglo XXI: situación y debate (1991-2012). Ciencias y Mar, XV (45): p. 19-62. México, 2011.

ORTIZ, A. Y DE LA LANZA, G. Diferenciación del espacio costero de México: Un inventario regional en Colección Geografía para el siglo XXI. Serie Textos Universitarios, No. 3, Instituto de Geografía, Universidad Nacional Autónoma de México, México, p.112-124, 2006.

PADILla, L. Y DE SICILIA A.. El Puerto De Salina Cruz ¿Zona Económica Especial: Futuro Incierto en Nuevos escenarios mundiales, repercusiones en México y potencialidades regionales. José Gasca Zamora y Lenin Martínez Pérez Coordinadores Libro Electrónico Instituto de Investigaciones Económicas, UNAM AMECIDER, México (2017).

PASANTES, J. Salina Cruz como Zona Económica Especial. Martes, 19 de diciembre de 2017 ID Conlines. Disponible en:https://idconline.mx/fiscal-contable/2017/12/19/salina-cruz-como-zona-economica-especial. Acceso 15 de octubre 2017.

PETROLEOS MEXICANOS (PEMEX). Se ejecutan acciones para la reanudación de operaciones en la refinería de Salina Cruz. Disponible en http://www.pemex.com/saladeprensa/boletines_nacionales/Paginas/2017-057-nacional.aspx. Acceso el 30 de junio 2017.

PRIEGO, A. BOCCO, G. MENDOZA, M. Y GARRIDO, A. Propuesta para la generación semiautomatizada de unidades de paisajes. Secretaria de Medio Ambiente y Recursos Naturales: Instituto Nacional de Ecología y Centro de Investigaciones en Geografía Ambiental, México, 2008.

RAMIREZ, L. G. M. Algunos efectos de la precipitación del huracán Paulina en Acapulco, Guerrero. Investigaciones Geográficas, n.37, p.7-19, 1998.

COSTA, W. M. A Ordem Ambiental Internacional. São Paulo: Contexto, 2011.

RODRÍGUEZ, O. Anuncia Murat Corredor Interoceánico en el Istmo de Tehuantepec. Disponible en: http://www.milenio.com/estados/Anuncia-Murat-corredor-interoceanico-tehuantepec_0_916708741.html. Acceso el 30 de mayo de 2017.

ROSS, J.; SANCHES. L. Ecogeografia do Brasil: subsídios para planejamento ambiental. São Paulo: Oficiana de Textos, 2009. 
SANCHEZ, B. El futuro de las relaciones puerto ciudad, Instituto Universitario de Puertos Marítimos, (2003). Disponible en: https://www.udc.es/iuem/documentos/monografias/puertoCiudad.pdf. Acceso 10 de enero de 2018.

SCHIRNER, G., ROBAINA, L. Zoneamento geoambiental da quarta colônia Rio Grande do Sul: uma análise integrada da paisagem. Revista Caminhos da Geografia, v.19, n.68, dez/2018, p.200-214, 2018.

\section{SECRETARIA DE COMUNICACIONES Y TRANSPORTES, ADMINISTRACIÓN PORTUARIA INTEGRAL DE} SALINA CRUZ (API SALINA CRUZ) Acerca del Puerto (2019). Disponible en:https://www.puertosalinacruz.com.mx/esps/0000202/acerca-del-puerto Acceso 10 de febrero de 2019.

SECRETARIA DE DESARROLLO AGRARIO, TERRITORIAL Y URBANO (SEDATU). Censo de Vivendas, Estado de Oaxaca, Município de Salina Cruz. (2017). Disponible em:http://transparencia.sedatu.gob.mx/\#. Acceso 12 de abril de 2017.

SECRETARIA DE DESARROLLO SOCIAL (SEDESOL). Sistema de Apoyo para la planeación Catalogo de Localidades, Salina Cruz. (2019). Disponible en:http://www.microrregiones.gob.mx/catloc/LocdeMun.aspx?tipo=clave\&campo=loc\&ent $=20 \&$ mun $=079$ Acceso $(23$ de enero de 2019)

SECRETARIA DE ECONOMÍA, (SE) Que es una Zona Económica Especial Autoridad Federal para el Desarrollo de las Zonas Económicas Especiales" 09/01/2017. (2017) Disponible en:http://www.gob.mx/zee/articulos/que-es-una-zonaeconomica-especial-9584?idiom=es (Acceso 12 de mayo 2017).

SECRETARIA DE HACIENDA Y CRÉDITO PUBLICO (SHCP) Y ZONAS ECONÓMICAS ESPECIALES (ZEE). Dictamen de la Zona Económica Especial de Salna Cruz (s/f) Disponible en:https://www.gob.mx/cms/uploads/attachment/file/372131/Dictamen_.pdf. Accesos20 de enero de 2019).

SECRETARIA DE MARINA, DIRECCIÓN GENERAL ADJUNTA DE OCEANOGRAFÍA, HIDROGRAFÍA Y METEOROLOGÍA (SEMAR DIGAHOM), "Salina Cruz, Oaxaca". Datos Generales del Puerto ((s/f) Disponible en: http://digaohm.semar.gob.mx/cuestionarios/cnarioSalinacruz.pdf. Acceso el 25 de mayo 2017

SEPÚlVEDA, D. Curso de Gestión de Terminales Portuarios. Comisión interamericana de Puertos OEA Autoridad Portuaria Dominicana. Ministerio de Relaciones Exteriores, Comisión Presidencial para la Modernización y Seguridad Portuaria Modulo Relación Ciudad Puerto. Santo Domingo, 2011.

SERVICIO SISMOLÓGICO NACIONAL (SSN) Instituto de Geofisica UNAM. México. Reporte especial: Sismo de Tehuantepec (2017-09-07 23:49 Mw 8.2). Actualizado el 28 de noviembre de 2017. (2017). Disponible en:http://www.ssn.unam.mx/sismicidad/reportes-especiales/2017/SSNMX_rep_esp_20170907_Tehuantepec_M82.pdf. Acceso 15 de septiembre de 2018.

SOUZA, M. L. Quando o trunfo se revela um fardo: reexaminando os percalços de um campo disciplinar que se pretendeu uma ponte entre o conhecimento da natureza e o da sociedade. Geousp - Espaço e Tempo (Online), v. 22, n. 2, p. 274-308, 2018 .

ZAMORA, T. Las Zonas Económicas Especiales, una oportunidad de desarrollo incluyente. Revista de Comercio Exterior, v.3, p.15-29, 2018. 